In Marine Productivity: Perturbations and Resilience of Socio-ecosystems. Proceedings of the 15th French-Japanese Oceanography Symposium.pp 161-167

2015

Eds Hubert-Jean Ceccaldi, Yves Hénocque, Yasuyuki Koike, Teruhisa Komatsu, Georges Stora, Marie-Hélène Tusseau-Vuillemin, Springer

ISBN 9783319138770

http://dx.doi.org/10.1007/978-3-319-13878-7 17

http://archimer.ifremer.fr/doc/00294/40489/

(c) Springer International Publishing Switzerland 2015

\title{
The Channel Programme: A Large-Scale Integrated Approach
}

\author{
Marchal Paul ${ }^{1,{ }^{*}}$, Carpentier Andre ${ }^{2}$, Foucher Eric ${ }^{3}$ \\ 1 Ifremer, Unité Halieutique de Manche mer du Nord, 150 quai Gambetta, BP 699, F-62321, Boulogne-sur-mer \\ Cedex, France \\ 2 Ifremer, Unité Lagons, Ecosystèmes et Aquaculture Durable en Nouvelle-Calédonie, 101 Promenade Roger \\ Laroque, BP 2059, F-98846, Nouméa Cedex, Nouvelle-Calédonie, France \\ 3 Ifremer, Unité Halieutique de Manche mer du Nord, Avenue du Général de Gaulle, 14520, Port-en-Bessin, \\ France \\ *: Corresponding author : Paul Marchal, email address : Paul.marchal@ifremer.fr
}

\begin{abstract}
:
The Channel programme is a collation of interlinked multidisciplinary projects supporting ecosystembased management in the English Channel by integrating works carried out in the past thirty years including novel approaches to the spatial modelling of ecosystems. The Channel programme has required a coordination of efforts and expertise by both scientists and stakeholders to address the challenges of the Marine Strategy Framework Directive and of its national implementations. The Channel programme has also consisted of harmonising information, regulations and habits in terms of ecosystem management in the English Channel.
\end{abstract}

Keywords : English Channel ; Marine environment ; Ecosystem-based management ; Impact of anthropic and environmental factors ; Scientific support to natural living resources management 


\section{Introduction}

The English Channel is an economically and ecologically strategic area of northwest Europe. It represents a significant economic zone where a number of human activities take place, and compete for space or resources: tourism and leisure, international ports and freight, exploitation of living and non-living resources.

The English Channel maritime domain concentrates around $20 \%$ of the worldwide maritime traffic, making it one of the most intensively used sea routes in the world, with 14 million passengers and 2.5 million crafts in 2008. The English Channel is rich in marine aggregates (sand and gravel) which are increasingly needed by British and French building industries. The English Channel is also rich in terms of biodiversity and commercial fishery resources. A number of commercial marine species can be found here, as well as many spawning, nursery and feeding areas, plus migration routes for fish, birds and marine mammals. The English Channel is the place where parts of the Atlantic and North Sea water masses intermingle. The physical configuration (e.g., bathymetry, coastline) of the English Channel contributes to specific hydrological structures (fronts, gyres, etc.) that control advection and the dispersal of marine organisms or pollutants.

The exploitation of natural resources (living resources such as exploited marine species but also mineral resources such as marine aggregates) generates substantial valued added at national and European levels. As a result, there has been an increasing societal and public demand from the governance (European Union, national governments and regional councils), industries (e.g., fishing and marine aggregate sectors of activity) and non-governmental organizations to provide a sound and integrated scientific support to ecosystem-based management in the English Channel. Of particular interest to the various stakeholders is the exploration of the English Channel ecosystem responses to global change.

An ecosystem-based approach to marine resources management requires the synthesis of existing scientific knowledge and its integration to new research. Such an approach is expected to improve the scientific basis to advice-giving and management. Key processes such as the interactions between species, between management strategies and exploited species, between environmental damage and the rest of the ecosystem, and interactions between conflicting human activities, cannot be understood by investigating each ecosystem component in isolation, but rather by exploring all aspects of the marine ecosystem, including the various sectors of activity, in an integrated fashion.

This objective requires a coordination of efforts and expertise by both scientists and stakeholders through international and multi-disciplinary projects to address the challenges of the Marine Strategy Framework Directive, and of its national implementations. Such a trans-régional approach also consists of harmonizing information, regulations and habits in terms of ecosystem management in the English Channel.

The English Channel ecosystem has been investigated by several research teams. Some European projects have fostered a multi-disciplinary approach targeted at marine living resources by integrating works carried out in the past thirty years including novel approaches to the spatial modeling of ecosystems. In this context, several scientific studies have engaged in the English Channel and the Southern North Sea to investigate:

- the assessment of key fish species;

- the characterization of their habitats; 
- the development of predictive modeling tools to evaluate the impact of human activities on the ecosystem;

- the contribution of the ecological niche in structuring commercial fish communities;

- the distribution and characteristics of spawning areas;

- the biogeographic identification of sole, red mullet and sea bass;

- the dynamics and strategies of fishing fleets;

- the dynamics and consequences of Phaeocystis blooms;

- the modeling of rivers inputs from the Seine, the Somme and the Escaut;

- the trophic capacities and resilience of the ecosystem following planned or unplanned human perturbations.

The objective of the ecosystem approach is therefore to understand more globally, at the scale of the Eastern Channel basin, the characteristics and the functioning of habitats and of the living resources they are home to. It will then become possible to apply an ecosystem approach to the management of marine resources in a broad sense (living, but also mineral and energetic resources), and to mitigate the pressure exerted by the different human uses and their adaptation to the ecosystem production capacities.

In this context, a multidisciplinary scientific initiative called the Channel programme was initiated in 2007, with the aim of increasing the knowledge on, and of better managing, this marine cross-border area. We present in this study the main objectives and provide insights into research projects that have contributed to these objectives since then.

\section{Objectives of the Channel programme}

The main objectives of the Channel programme are the following:

- to collectively develop research capacity to achieve a multi-disciplinary understanding of the functioning of marine and coastal ecosystems subject to strong human pressure;

- to promote the sustainable management of the different parts of the English Channel by developing decision-taking tools with the aim of adapting human use intensity to the withstanding capacity of ecosystems;

- to provide indicators to decision-makers with the aim of, (i) characterizing the status of ecosystems, (ii) measuring the pressure exerted by diverse human activities on these ecosystems and, (iii) evaluating the efficiency of management measures.

To achieve these objectives, the Channel programme has been structured into 4 main research axes:

- describing ecological factors structuring the distribution of fishery resources : habitats (abiotic and biotic factors), biotopes, assemblages, life history of main species, environment;

- understanding the functioning of the food web : description, interactions between primary (including toxic phytoplanktonic species) and secondary production and fishes, functioning, sensitivity to perturbations;

- quantifying the impact of human pressure on habitat and food web : fisheries, marine aggregates extraction, offshore wind farms, pollutions; 
- defining new management strategies for sustainable resource exploitation respectful of marine environment and biodiversity.

\section{$3 \quad$ Research and governance projects}

The launching of the Channel programme in 2007 has fostered the development of several EU-funded projects with a central research or governance component. These complementary and inter-linked projects (Table 1) have involved several hundreds of research scientists and several dozens of research organisms (e.g., governmental institutes, universities) in the EU, and even abroad (e.g., collaboration between IFREMER $^{1}$ in France and $\mathrm{DFO}^{2}$ in Canada).

Table 1. Contribution of the eleven projects building in the Channel programme to the understanding of ecosystem elements and of the human pressures impacting them (1-7, 9, 11: EU-funded CHARM1, CHARM2, CHARM3, CRESH, CAMIS, VECTORS, DYMAPHY, MEMO, SOCIOEC; 8, 10: French agencies funded COMANCHE, EMIBIOS.

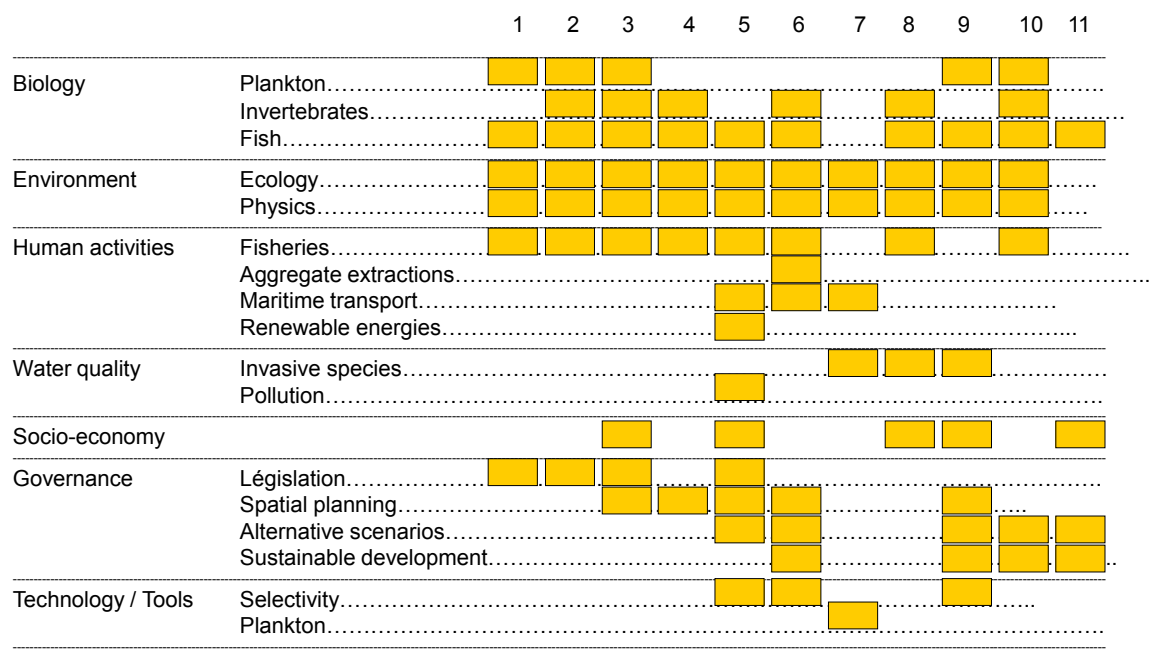

We present below the background and objectives of a selection of these projects.

\subsection{EMDI+ and CAMIS projects}

EMDI+ and CAMIS are two successive EU INTERREG-funded governance projects that have been coordinated by the Region Haute-Normandie in France.

The EMDI+ (Espace Manche Development Initiative) project - INTERREG IIIB North West Europe, strongly contributed to the development of the political cooperation between France and the UK across the English Channel ("Channel Arc Manche" cooperation) between 2004 and 2008. The main objectives of the EMDI project were to work out a strategic vision, to test new cooperation avenues, to develop greater knowledge of the Channel area and the issues at stake, in particular through the crea-

\footnotetext{
${ }^{1}$ Institut Français de Recherche pour l'Exploration de la Mer

${ }^{2}$ Department of Fisheries and Oceans
} 
tion of a cross-Channel atlas. This project brought some convincing arguments for the recognition of the Channel Arc Manche as a coherent co-operation area in Europe. It has also highlighted the opportunity for the Channel area to position itself as a demonstration maritime basin of the integrated maritime policy championed by the European Commission. More details on this project may be found on http://www.emdi.certic.unicaen.fr/en/news.html.

The more recent CAMIS (Channel Arc Manche Integrated Strategy) project (https://camis.arcmanche.eu/home/) has confirmed this position, with the objectives of, (i) developing a framework for maritime governance, (ii) providing expertise for Channel Arc Manche and decision-makers in the Channel area and, (iii) stimulating cooperation that addresses strategic issues at stake. To meet these objectives the project integrated of the contribution of other projects which developed scientific knowledge, in particular the CHARM project (see below), or sector-based strategies for the Channel area e.g. ports and transport, maritime safety.

\subsection{CRESH project}

The CRESH project (Cephalopod Recruitment from English Channel Habitats) addresses the Priority 4 of the Interreg IV A programme which concerns the sustainable environmental development of the common space (http://www.unicaen.fr/ufr/ibfa/cresh/?lang=en). Cephalopods are short-living species, their abundance depends on the annual recruitment (juveniles entering the exploited stage) and they are directly concerned by this theme. The project gathers eight Franco-British partners from universities, research institutes and fishermen's organisations. This brief introduction underlines complementary skills gathered to better understand these animals and the part that they play in the English Channel ecosystem.

\subsection{CHARM1, CHARM2 and CHARM3 projects}

CHARM1 and CHARM2 have been two successive French-British cooperation projects, co-funded under the UE Interreg programme, through the Haute-Normandie Region and the Government Office for the South-East. Each of these projects developed an atlas as a "toolbox" to support decision-making and spatial planning in relation to the sustainable management of the English Channel marine resources. The first phase (2003-2005) covered the Dover Strait and the second one (2006-2008) covered the whole Eastern English Channel. These projects have also been a good opportunity to gather and harmonize French and UK ecological and environmental data. The Channel Habitat Atlas for marine Resource Management produced during CHARM2 can be downloaded on http://archimer.ifremer.fr/doc/2009/rapport-7377.pdf

The CHARM3 project is the logical follow-up to CHARM1 (2003-2005, 1.1 M€, 5 partners) and CHARM2 (2006-2008, 2.1 M€, 6 partners). Firmly grounded on results obtained in the previous phases, the overarching objective of CHARM3 was to conduct multidisciplinary studies through an ecosystem-based approach, where human beings are considered as an integral part of the ecosystem. Compared to CHARM1 and CHARM2, the CHARM3 has been extended to the entire English Channel and the southern part of the North Sea and new research areas (economics, climate change) have been investigated. CHARM3 combined a wide range of expertise fields, including marine sciences (oceanography, marine biology, fishery science), economics, legislation, geography (e.g., cartography, spatial analysis, Geographical 
Information Systems), statistical and conceptual modelling (habitat and trophic network models), marine conservation planning and information technologies (e.g., web technologies, programming). Many of these skills are interdisciplinary by nature, an essential aspect for any integrated approach. Seventeen French and British partners have been involved in the project, and pursued three main groups of actions: (i) collection and standardisation of information, (ii) integration of information and, (iii) development of tools to disseminate information.

\subsection{VECTORS project}

The on-going EU FP7-funded VECTORS project (Vectors of Change in Oceans and Seas Marine Life, Impact on Economic Sectors) (2011-2015) acquired considerable knowledge on the effects of past, present and future vectors of change on the marine environment. Pressures could be direct (e.g., maritime freight as invasive species vector, climate change and ocean acidification, intensive living and mineral resources exploitation), or indirect (e.g., energy-producing devices, demographic pressure on the coasts, tourism, recreational activities). The VECTORS project is particularly investigating how vectors of change and their interactions result in changes in three specific processes: blooms of non-endemic and non-indigenous species, spreading of endemic species and changes of commercial species distribution and productivity. More details on the VECTORS project, including scientific production, may be found on http://www.marine-vectors.eu/

\subsection{COMANCHE project}

King scallop (Pecten maximus) is an important species in the English Channel, notably as it constitutes the first species in landings (15 to 20000 tons per year) for the French fishing fleet (700 fishing vessels) based in this maritime area. Due to its economic importance, several scientific studies have been conducted on this species, but mainly at local scales. Moreover, despite the basic knowledge acquired through these studies, several points of the scallop dynamics remain poorly understood. Additionally, episodic perturbations (e.g., introduction of competitor, development of toxic algal blooms) have affected the king scallop populations in unpredictable ways, making it even more difficult to apprehend the dynamics of the populations and their interactions with the rest of the ecosystem. In this context, the on-going COMANCHE (COquilles Saint-Jacques de la MANCHE) project (2012-2015), co-funded by the French National Research Agency), aims at improving our knowledge on the relationship between king scallop and its ecosystem, in an integrated fashion, and over the whole English Channel. The characteristics and the structure of the exploited populations of king scallop have been investigated, with the objective of determining the position of this species within the English Channel ecosystem, and of quantifying the impacts associated to its exploitation. These objectives are being through a multi-disciplinary approach, involving physicists, biologists, economists, but also regional stakeholders (e.g., fisheries regional committees). More details on the COMANCHE project may be found on: http://wwz.ifremer.fr/defimanche/Projets/En-cours/COMANCHE. 


\section{$4 \quad$ Partnership}

The projects conducted within the Channel programme involved a wide and multidisciplinary partnership, which is presented in the Table below.

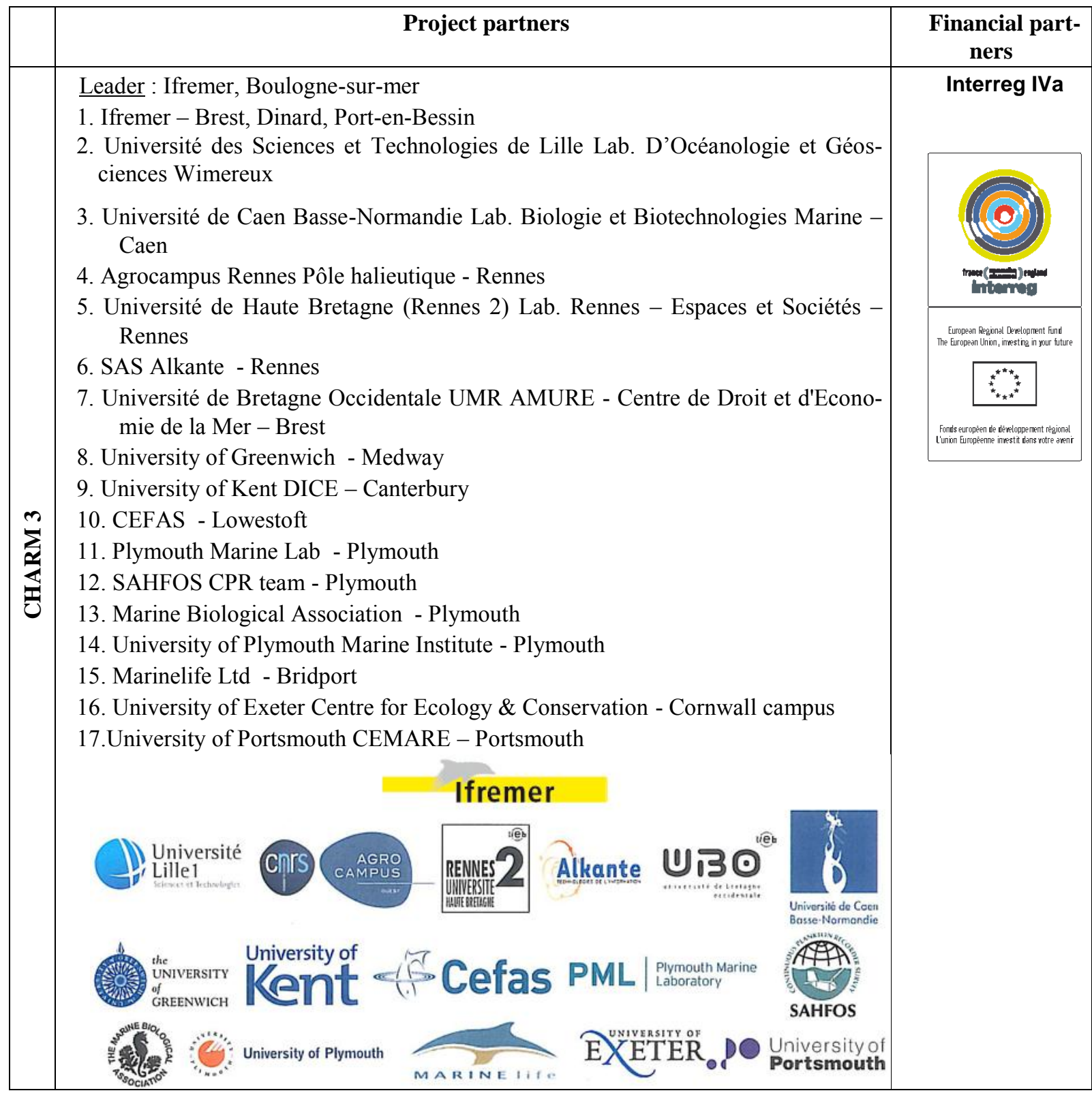




\begin{tabular}{|c|c|c|}
\hline 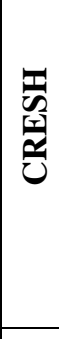 & $\begin{array}{l}\text { Leader : Université de Caen Basse-Normandie } \\
\text { 1. The Marine Biological Association of the UK } \\
\text { 2. Devon Sea Fisheries Committee } \\
\text { 3. Royal Holloway University of London } \\
\text { 4. Centre for Environment, Fisheries \& Aquaculture Science } \\
\text { 5. Ifremer Boulogne/mer - Centre Manche Mer du Nord } \\
\text { 6. Comité Régional des Pêches Maritimes de Basse Normandie } \\
\text { 7. University of Plymouth }\end{array}$ & 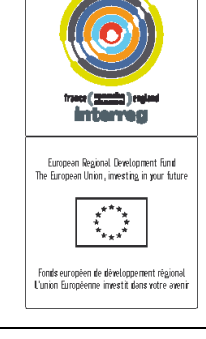 \\
\hline 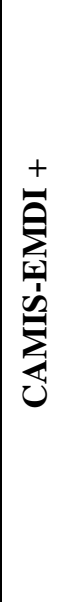 & $\begin{array}{l}\text { Leader: Région Haute-Normandie } \\
\text { 1. Régions Bretagne } \\
\text { 2. Région Nord Pas-de-Calais } \\
\text { 3. Région Picardie } \\
\text { 4. Région Basse Normandie } \\
\text { 5. West Sussex County Council } \\
\text { 6. Cornwall County Council } \\
\text { 7. Kent County Council } \\
\text { 8. Southampton City County Council } \\
\text { 9. Devon County Council } \\
\text { 10. Conseil Général Côtes d'Armor, } \\
\text { 11. Hampshire } \\
\text { 12. Université de Caen } \\
\text { 13. Marine South East } \\
\text { 14. SEEDA }\end{array}$ & 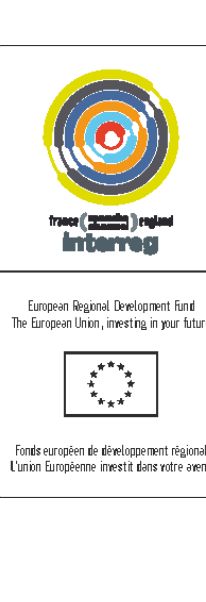 \\
\hline
\end{tabular}

\section{Conclusion}

The Channel programme feeds in long-term sustainable management of the marine resources in the English Channel through the development of ecosystem and conservation planning models. Model scenarios and outputs contribute to regional environmental planning and support the management of the living resources and assessments of potential impact of human pressures. The outputs of the many projects building in the Channel programme enhance our understanding of the English Channel marine ecosystem and, in doing so, improve management performances. The multidisciplinary character of the Channel programme is then particularly relevant in the context of the MSFD which, through a holistic approach of the seas and oceans, seeks to achieve a good ecological status for the marine environment by 2021 .

The Channel programme has been successful bringing together scientists and stakeholders. It has demonstrated, through bi-annual conferences, during which scientists presented and discussed their results with managers, the value-added of grouping research teams of different backgrounds and fields of expertise (e.g., ecologists, sociologists, economists). It has further evidenced to decision-makers that managing a common maritime domain requires an ecosystem approach integrating all the human activities impacting the marine environment.

More details on the Channel programme may be found on the URL: http://wwz.ifremer.fr/defimanche. 